\title{
Comparing contractors' decision to bid in different market environments
}

Bee-Lan Oo and Derek $S$ Drew (Department of Building and Real Estate, Hong Kong Polytechnic University, Kowloon, Hong Kong) and Hing-Po Lo (Department of Management Sciences, Hong Kong City University, Kowloon, Hong Kong)

ABSTRACT

The competitive situations within the Australia, Hong Kong and Singapore construction market environments are compared by observing the contractors' decision to bid behaviour according to two extreme market conditions (i.e. booming and recession) and different number of bidders scenarios (ranging from 4 to 30). Data were collected via a designed experiment so as to make direct comparisons possible. This study provides evidence that contractors' decision to bid behaviour varies in different market environments. Inline with decreasing probability of winning, the 'bid' responses of the three groups of contractors decrease as the number of bidders increases. However, all Australian respondents declined to bid when the number of bidders exceeded 10, even in recession. This is in stark contrast to Hong Kong and Singapore where about $30 \%$ of respondents were willing to bid in competitions containing 30 bidders, even in boom periods. In addition, the 'bid' responses of Australia were higher in booming than in recession times when the number of bidders, $N \leq 4$. The Hong Kong construction market environment was found to be the most competitive with considerably higher proportions of 'bid' responses; this was followed by the Singapore and Australia, respectively.

Keywords: bidding, decision to bid, Australia, Hong Kong, Singapore

\section{INTRODUCTION}

Contractors adopt various strategic approaches in their decision to bid to enhance chances of winning work. They do not always bid for every job that comes along but to select from a continually changing array of potential projects (Odusote and Fellows 1992). Male (1991) suggests that contractors define a strategic domain at the corporate strategy level with the domain establishing the market dimensions within which contractors plan to operate and compete for work. Contractors then make decisions on which contracts to bid for at business strategy level. The strategic domain within which contractors compete for work can be defined by different parameters including the degree of complexity and size of project, the types of contractual arrangement and geographical area (Hillebrandt 2000).

The environment, however, has an especially dominant influence on the construction market and, hence, on the contractors' competitive strategies (Pries and Janszen 1995). They equated 'environment' with the 'governmental regulations' that form the centre forces in influencing the construction market. The government acts as the industry regulator (e.g. environmental, financial and technical regulations) and balances the construction demand and supply via building approval quotas, business licensing conditions and procurement methods. Consequently, the governmental regulations exert varying degrees of influence on competition in the industry that can be represented along the continuum of high-low. In Australia, for example, the competitive situation within the construction industry is highly regulated. The Australian Government have published sets of codes of practice together with implementation guidelines dealing with tendering issues both at the national and state or territory levels (e.g. The New South Wales Government Code of Practice for Procurement). Whilst at the low end, bidding competition flourishes in the free market environment in Hong Kong with little intervention from the government on any trades. Contrary to Hong Kong, it appears that the Singapore Government intervention on competition may fall somewhere along the high-low continuum since the government resumes a more active role in shaping the competition in the construction industry (Ofori and Chan 2001). One of the major issues a contractor faces when bidding is how to approach the competitive situation, which may be subjected to varying degrees of government intervention on competition. Dyer et al. (1989) suggest that success in bidding competition is in part a function of knowledge about a particular market environment.

This paper compares the competitive situations within the Australia (AUS), Hong 
Kong (HK) and Singapore (SIN) construction market environments. The focus is on comparing contractors' decision to bid behaviour according to different market conditions and number of bidders. The specific objectives are to: (i) compare the contractors' willingness to bid in situations of varying competition intensity (number of bidders) at the times of two extreme market conditions, i.e. boom times with low need for work, and recession times with high need for work; and (ii) compare the corresponding 'bid' responses among the three groups of contractors.

\section{DECISION TO BID, MARKET CONDITIONS AND NUMBER OF BIDDERS}

One of the major issues a contractor faces in bidding is deciding whether or not to compete. Bid/no-bid decision (also known as project selection) is a vital and recurring strategic decision for construction firms given that a significant portion of industry workload is let by competitive bidding. Thorpe and McCaffer (1991) highlight that contractors strive to balance market opportunities and risk in their decision to bid. They go on to point out that contractors will try to avoid contract that is too large for their size, beyond their experience range and normal geographical area of operation, and the contract is likely to stretch their available resources including cash. Skitmore (1989) classified the contractors' project selection objectives into three main headings, namely monetary, non-monetary and market-related objectives. The monetary objectives are concerned with the desired changes in levels of monetary resources, i.e. in terms of profit or profitability. Also, the identified non-monetary objectives include: to keep the resources occupied, to serve the client well, to maintain and improve quality and services; and finally, market-related objectives are: to increase market share, to stay in existing markets and to penetrate new markets.

According to Econ (2004), two important factors take place in a bidding competition are market conditions and number of bidders. These two factors have also been identified as important in separate surveys, undertaken by Ahmad and Minkarah (1988), Shash (1993) and Fayek et al. (1998). The prevailing market conditions oscillate between periods of economic boom and recession. Thorpe and McCaffer (1991) regard market conditions as a subjective term which on a macro-industry level includes such factors as the total construction order for all type of works and construction price levels whilst on a microcompany level includes competitor activity and construction opportunities in local, national and international markets. De Neufville et al. (1977) found that market conditions strongly affect contractors' bidding behaviour and provide evidence of a relationship between the market conditions and intensity of competition (i.e. number of competing bidders). The authors found that less bids were recorded in what they refer to as 'good' years whereas competition becomes fierce in 'bad' years when fewer projects are available.

The number of bidders is the key variable in probabilistic approach for construction pricing as defined by Friedman's (1956) tendering theory. Akintoye and Skitmore (1992) suggest that the number of competing bidders reflects the capacity of the industry in terms of 'active' market players capable to undertake a project, and thus provides a measure of degree of competition in the industry. De Neufville and King (1991) highlight that contractors are reluctant to bid in competition consisting large number of bidders as probability of winning decreases, this will also increases contractors' overheads and ultimately costs the owners more. Highly correlated with the number of bidders are the bidding costs. There has been much debate on the ideal number of bidders given its direct bearing on bidding costs (e.g. Flanagan and Norman 1985, Wilson et al. 1987, de Neufville and King 1991). Ngai et al. (2002) suggest that clients should vary the minimum number of bidders in any new bidding situation with prevailing market conditions in order to obtain the most competitive bids in the most cost-efficient way. Runeson (2000), on the other hand, argues that the question whether the number of bidders is independent of market conditions or is it a function of market conditions may not be so important since empirical studies have shown quite conclusively that contractors' bidding behaviour is significantly affected by number of bidders (e.g. Carr 1983, King and Mercer 1990, Skitmore 2002).

\section{INDUSTRY STRUCTURES}

AUS, HK and SIN were chosen for comparison in this study mainly on the basis that they have a Commonwealth background, and that the construction industries are based on British model. The traditional procurement of designbid-construct predominates in the industries in which competitive bidding is used extensively as mechanism for job distribution.

The construction industry structures of AUS, HK and SIN share the dominant structural characteristics of the construction industry wherein: 
(i) there are large number of small firms and comparatively few large companies in the industry;

(ii) competitive subcontracting is wellestablished and used extensively in project delivery; and

(iii) the government being the dominant client act as the industry regulator.

At the end of June 2003, there were 339,982 construction businesses operating in AUS, but only 1,354 of the construction firms earning $\mathrm{A} \$ 10$ million or more that made up $42.1 \%$ of the total turnover of the industry (Australian Bureau of Statistics 2004). Given its large geographical area, the vast majority of construction firms in AUS are state-based, and often only in one region within that state (Underhill 2003). On the other hand, the size and variety of construction projects in SIN and HK are constrained by the city states' small physical size. The HK Census and Statistics Department (2004) estimated that the total number of construction-related establishments in HK approaching 20,000 in 2002 , whereas there are 60 firms eligible to public contracts above HK\$ 50 million (Environment, Transport and Works Bureau 2005). In SIN, there are 5,327 construction-related firms as listed in the Singapore Building Construction Authority's (BCA) Contractors Registry (2005). Of these, only 40 firms from both the building and civil engineering sectors are of unlimited tendering limits. These figures on number and size of firms serve as an indicator of the degree of competition within the industries.

\section{COMPETING IN AUSTRALIA, HONG KONG AND SINGAPORE}

In comparing the three countries/territories, AUS has a prosperous Western-style capitalist economy. The Australian Government is committed to ensuring that the industry continues to strive to attain its maximum potential in ways that are productive, flexible and fair (Department of Employment and Workplace Relations 2006). The commitment of Australian Government is well reflected in the publication of codes of practice and implementation guidelines for the industry, both at the national and state or territory levels. In July 2005, the announcement on further extension to the application of the industry codes and guidelines with mandatory effect to all entities tendering for or expressing interest in construction projects directly or indirectly funded (including privately funded Australianbased construction projects) by the Australian Government (Department of Employment and Workplace Relations 2006), perhaps is the most significant shift towards highly regulated Australian construction industry. With this in mind, the influence of the Australian Government on the industry is strong (Department of Industry, Science and Resources 1999), which shapes the risks and the nature of competition that the construction firms experience. It is worth noting that the implementation guidelines advocate for embracing ethical principles in competitive behaviour towards reduced cost and continuous improvement in bidding process (Australian Procurement and Construction Council 1999). Pre-qualification is practised for majority of the public sector work (Davis Langdon and Seah 200). Wilson et al. (1987) found that there were 4.81 bidders per project in average for open bidding of number of bidders ranging from one to maximum of seventeen bidders per project, and only $5 \%$ of the 286 project data sample attracted more than ten bids.

HK operates a laissez faire economy with a clear political, legal and ethical business environment that is favoured by foreign firms (Lasserre and Probert 1998), not to mention the government has not placed any legal or institutional restrictions on the entry of foreign contractors. The government intervention in economic matters based on the laissez faire economic policy is mostly confined to regulating against force and fraud among market participants. Large numbers of contractors are often encouraged to bid in HK. For example, a recent public sector data set from year 1990 to 1996 identified that the number of bidders per project ranging from 3 to 33 with an average of 14 bidders (Ngai et al. 2002). The local construction market is thus highly competitive in which lowest bids tend to succeed, although price is not the only criterion for contractor selection.

The SIN construction industry is well managed with large number of foreign contractors active in the market. A number of methods of competition have been employed by the foreign contractors in SIN including joint venture with local firms and provision of finance, new technologies and designs for projects (Ofori 1996). In contrast to the HK Government, the SIN Government resumes a more active role in shaping the operating environment and so the degree of competition in the construction industry (Ofori and Chan 2001). They found that the local large construction firms have placed high emphasis on the government helps towards their growth. It is worth noting that most of the local construction firms are owned by Chinese 
Singaporeans and have a Chinese-oriented business structure (Ang and Ofori 2001). Above all else, the local construction market is highly competitive with long tenderer list in bidding competition. Oo and Drew (2005) identified that the number of bidders per project ranges from 6 to 31 with an average of 15.7 bidders based on 46 public sector contracts from year 2002 to 2004. The intensity of competition in SIN construction market is beyond doubt and well demonstrated in which 28 bidders have bid for a design and build project, consisting both local and foreign contractors (The Straits Times 2004).

The review suggests that government intervention on competition within the industry varies widely from country to country. It is beyond the scope of this paper to cover different sets of procurement procedures and rules; rather, we focus on the competitive situations within the three construction market environments that are subjected to varying degrees of government intervention by observing the contractors' decision to bid behaviour.

\section{BIDDING EXPERIMENT METHOD}

Given the overall aim of comparing contractors' decision to bid behaviour in AUS, HK and SIN, it was decided to develop a controlled design research game, i.e. a bidding experiment that permits the following:

(i) direct comparisons among the three construction market environments;

(ii) stricter control and active manipulation of variables; and

(iii) examination of the effect of number of bidders on contractors' decision to bid, as bid/no-bid decisions for several possible number of bidders scenarios are unobtainable in 'real world', where contractors only submit one-off bid in bidding for a project.

The bidding experiment method adopted was developed from Dyer's (1987) experimental design in which the author studied the effect of number of bidders on seller's revenue by asking the experiment subjects to bid in two hypothetical scenarios of three and six bidders, respectively. In this case, the experimental approach increases the assurance that any changes in the outcome of decision to bid are a consequence of the interventions, i.e. changes in market conditions and number of bidders. In addition, the bidding experiment was complemented by follow-up interviews designed to avoid any significant omissions or misunderstandings of the bidding process, and to disclose contractors' rationale in their decision to bid that would not otherwise have been revealed. It is worth noting that experimental approach has been used in construction bidding research as early as 1970 by Hackemer (1970) and most recently by Drew and Skitmore (2006). Indeed, Meikle (1990) pointed out that several international comparisons of construction costs and prices are moving towards the adoption of experimental approach by engaging experts in each country.

The experiment subjects are (i) Group C contractors listed in the HK Environment, Transport and Works Bureau's (ETWB) List of Approved Contractors for Public Works (2005), and (ii) Group A1, A2 and B1 contractors listed in the SIN BCA Contractors Registry (2005). A desk study on past tender reports revealed that these groups of contractors are 'active' market players. All construction firms on both the ETWB and BCA lists were contacted and no conscious effort was made to exclude the listed foreign contractors. The AUS respondents, on the other hand, were recruited via personal contacts considering the large number of firms in the industry as highlighted earlier. Indeed, Fayek et al. (1998) used the same sampling approach in his Australian-based survey on tendering practices.

Senior management of the construction firms with experience in bidding were invited to participate via email in the bidding experiment by (i) acting as senior managers of their construction firms, and (ii) bidding for a total of twenty projects. These were arranged in two rounds according to two extreme market conditions scenarios, i.e. (i) boom times with low need for work, and (ii) recession times with high need for work. This was done to obtain a distinctive comparison of results and to reflect the industry norm in which prevailing market conditions is seen as the proxy variable for the contractors' need for work (de Neufville et al. 1977).

The twenty projects, based on past tender reports, are lump sum procurement of conventional projects. Apart from key information, such as project type, client and location, respondents were also given an identical cost estimate derived from the lowest bid prices in past tender reports and they were required to decide which jobs to bid for. Changes were made to the experimental instrument as necessary to reflect the local bidding practices, for example, the term 'conversion and extension' was referred to upgrading and maintenance jobs for $\mathrm{HK}$, 
whereas the term 'addition and alteration' and 'alteration' were used for SIN and AUS, respectively. Considering the possible number of bidders scenario, the estimated number of bidders for the AUS case increasing in the level of 2, 4, 6, 8, 10, 15 and 20 as compared to $N=4$ to 30 for $\mathrm{HK}$ and $\mathrm{SIN}$ (i.e. $4,6,8,10$, 14, 18, 24 and 30). This was done to reflect the local competitive situation as the maximum number of bids received was 17 for AUS (Wilson et al. 1987), 33 for HK (Ngai et al. 2002) and 31 for SIN (Oo and Drew 2005). In addition, these intervals enable a close examination of bidding patterns when there is less number of bidders, and to reduce the repetitive nature of the experiment since divergence in bidding decisions is expected to be less noticeable if there are too many bidders (Wilson et al. 1987). Respondents were asked to bid up to the bidding scenarios of $N$ bidders that they wish to bid.

\section{EXPERIMENT LIMITATIONS}

Setting up a bidding experiment which is an exact replica of the commercial construction industry is extremely difficult, if not impossible to do, since there are so many possible factors affecting decision to bid (e.g. Egemen and Mohamed (2007) identified 83 decision to bid factors). The focus has therefore been on two important factors in a bidding competition, i.e. market conditions and number of bidders. Other factors in the experiment are held constant (i.e. project duration, location, contract type, client type) in establishing a setting that the subjects are familiar with, thus allowing their experience to manifest itself effectively.

The experiment also does not consider the direct effect of bidding decisions on future events since the 20 projects were released at once. No feedback information is given to the respondents at the end of each round as both round of the experiments are independent, being based on different market conditions scenarios. It is felt that inclusion of 20 projects is necessary to generate a reasonable data set and to reflect that contractors are selective in their decision to bid given that bid enquiries are received continuously. It is also recognized that the subjects tend to be more risk seeking in an experimental setting, although it is believed that industry practitioners who are willing to spend times on non-rewarding academic studies (in this case two rounds of experiment) will respond genuinely since many stated they would do so.

\section{SAMPLE PROFILE}

A total of 60 construction professionals participated in the bidding experiment for two rounds. Of these, 11 were from AUS, 18 from HK and 31 from SIN. The overall response rates for $\mathrm{HK}$ and $\mathrm{SIN}$ are $30.0 \%$ and $30.7 \%$, respectively. For the AUS respondents, the response rate is $64.7 \%$ based on a total of the 17 invitations sent through personal contacts. Nine of the AUS respondents were from New South Wales, two from Melbourne and one from Perth. A majority of them are chief or senior estimators of large construction firms with 8 to 30 years of experience in the industry. While for the HK and SIN respondents, around $90 \%$ of them are from senior management level including director, managing director, estimating and contracts manager who have background experience in bidding. Also, the $\mathrm{HK}$ and SIN respondents have an average of 21 and 20 years of experience in the industry respectively, and around $70 \%$ of them involved in 80 to $100 \%$ of their organization bidding exercise.

\section{COMPARING CONTRACTORS' WILLINGNESS TO BID}

Table 1 shows the percentages of the AUS, $\mathrm{HK}$ and SIN respondents opted to bid according to market conditions and number of bidders. Although the experiment design for the AUS respondents was based on $N=2$ to 20 , it can be seen that all AUS respondents declined to bid when the number of bidders exceeded 10 , even in recession. The increase in number of respondents opted to bid when $N$ $=10$ in recession can be explained because fewer jobs are available in recession. The AUS respondents pointed out that number of bidders and bidding costs are their main concerns in bid/no-bid decision. It is worth noting that number of bidders was identified as being the most important factor affecting contractors' bid/no-bid decision in New South Wales, Australia (Bajaj et al. 1997). In contrast to severe competition in early 1980s (Wilson et al. 1987), the findings seems to indicate that the AUS contractors' competitive behaviour embraces the ethical principles that aim to reduce cost and continuous improvement on bidding process advocated by the Australian Procurement and Construction Council (1999).

A stark contrast to the AUS respondents, at least $30 \%$ of the $\mathrm{HK}$ and SIN respondents opted to bid in competition consisting 30 bidders, even in boom periods. For the HK case, it can be clearly seen that $50 \%$ of the respondents were willing to bid in competition of 30 bidders in recession times, and those responded to the follow-up interviews agreed 
that more bidding attempts will at least increase the hit rate in surviving during hard times. Dyer and Kagel (1996) refer this phenomenon as simple survivorship pressure that applied to both the new market entrants as well as experienced contractors. On the other hand, $33 \%$ of the $\mathrm{HK}$ respondents who still submitting bids in boom times when number of bidders is considered large highlighted that this was done to fulfil other pricing objectives, for example, to maintain the relationship with client and to get a feel for the market. Indeed, the interviewees expressed that they are 'numb' to the intense competition in the HK construction market and perceive there is little point to consider number of bidders in their bidding decisions. et al. (2001).

\section{COMPARING THE PROPORTIONS OF 'BID' RESPONSES}

The total number of 'bid' responses received from the AUS, HK and SIN respondents were 1045,3141 and 3560, respectively as shown in Table 2. The corresponding average number of times each respondent bid within each group was 95, 175 and 115. Each respondent from $\mathrm{HK}$ on average bid approximately twice as much as AUS respondent. A chi-square test shows that there is a significant difference in the bid/no-bid responses for the three groups of respondents $\left(x^{2}=604.91 ; d f=2 ; p=0.001\right)$. The phi

\begin{tabular}{cccc|ccc}
\hline No. of bidders, $N$ & \multicolumn{6}{c}{ \% of respondents opted to bid } \\
\cline { 2 - 7 } & \multicolumn{3}{c}{ Boom } & \multicolumn{3}{c}{ Recession } \\
\cline { 2 - 7 } & AUS & HK & SIN & AUS & HK & SIN \\
\hline 2 & 100 & - & - & 100 & - & - \\
4 & 100 & 100 & 100 & 100 & 100 & 100 \\
6 & 91 & 100 & 100 & 91 & 100 & 100 \\
8 & 55 & 83 & 94 & 55 & 100 & 100 \\
10 & 27 & 67 & 90 & 45 & 83 & 90 \\
14 & - & 50 & 71 & - & 72 & 87 \\
18 & - & 39 & 42 & - & 61 & 65 \\
24 & - & 33 & 29 & - & 50 & 39 \\
30 & - & 33 & 29 & - & 50 & 35 \\
\hline
\end{tabular}

Table 1: Respondents opted to bid according to market conditions and number of bidders

Considering the SIN cases, those declined to bid agreed that it is a waste of resources to bid when number of bidders becomes unreasonably large. They complained that bid prices are always on the low side if there are too many bidders, particularly in recession, and someone who makes a big mistake in pricing will win the job.

This group of contractors urged a paradigm shift in the local contracting practice concerning extensive use of competitive tendering involving too many companies, and clients' focus on the lowest price in awarding contracts. It is worth nothing that SIN contractors have made the similar recommendation in an earlier study by Dulaimi measure shows a low to moderate association between the bid/no-bid responses and country/territory $(\varphi=0.18 ; p=0.001)$. These results are not surprising given that contractors operating in different construction market environments are unlikely to be similar in their decision to bid behaviour. The more relevant question concerns the proportional differences in 'bid' responses among the groups.

Table 3 shows the proportional differences of 'bid' responses at 95\% confidence interval and the sample odds ratio through paired-group comparisons. It can be seen that the lower and upper bounds of the confidence intervals for both the AUS vs. HK and AUS vs. SIN comparisons are negative, suggesting that the

\begin{tabular}{lccr}
\hline & \multicolumn{2}{c}{ Decision to bid } & \\
\cline { 2 - 3 } Country/ territory & Bid & No-bid & Total \\
\hline AUS & $1045(33.9)$ & $2035(66.1)$ & 3080 \\
HK & $3141(54.5)$ & $2619(45.5)$ & 5760 \\
SIN & $3560(35.9)$ & $6360(64.1)$ & 9920 \\
\hline
\end{tabular}

Note: \% of total in parentheses

Table 2: Bid / no bid responses according to country / territory 
probability of a 'bid' decision for AUS is lower than the HK and SIN respondents. Further evidence can be found in the sample odds ratio wherein there were 43 'bid' responses from the AUS respondents for every 100 'bid' responses from the HK respondents. The estimated odds of a 'bid' response are 2.32 (i.e. 1/0.43) times higher for the HK than the AUS respondents. Interestingly, the difference in proportions of 'bid' responses between AUS and SIN is less than 0.04 (i.e. -0.0387, 0.0004 ), even with about $30 \%$ of the SIN respondents opted to bid up to $N=30$ as discussed earlier. This seemingly small difference can be partly explained because the Singapore respondents are very selective in their decision to bid for competition consisting large number of bidders, and thus fewer bids were submitted. As described earlier, they are concerns about the bidding costs and project profitability; perhaps they will only bid for projects fall within their organization strategic domain. The estimated odds of a 'bid' response are only 1.08 (i.e. 1/0.92) times higher for the SIN than the AUS respondents. Considering the paired-comparison between HK and SIN, the positive confidence intervals (i.e. $0.17,0.20$ ) suggest that the probability of a 'bid' decision for HK is 17 to $20 \%$ higher than the SIN respondents. Although the HK and SIN respondents' willingness to bid appears to be quite similar, the estimated odds of a 'bid' response for HK are 2.14 times higher than the SIN respondents. This paired-group analysis suggests that the construction market environment in $\mathrm{HK}$ is the most competitive among the three as reflected in its considerably higher estimated odds of a 'bid' response as compared to the SIN and AUS respondents.

Figure 1 shows the breakdown of proportions of 'bid' responses according to country/ territory, market conditions and number of bidders. Inline with decreasing probability of winning, it can be seen that all AUS, HK and SIN respondents' proportions of 'bid' responses decrease as the number of bidders increases. However, the AUS case was something of a surprise in which higher proportions of 'bid' responses were recorded in booming than in the recession scenario when $N=2$ to 4 . This is contrary to the general belief that contractors bid more in recession when fewer jobs are available. It can also be clearly seen that there are rapid drops in proportions of 'bid' responses for the AUS case when $N>$ 4, taking 100 opportunities to bid, only three bids were recorded when $N=10$ in boom periods. As revealed in the discussions, some of the AUS respondents noted that they are keener in competition of less bidders, $N=2$ to 4 given the higher probability of winning.

Both $\mathrm{HK}$ and SIN respondents generally bid more in recession when competition becomes fierce. These phenomenons are similar to that of de Neufville et al. (1977). However, the HK proportions of 'bid' responses for both the booming and recession scenarios are considerably higher than SIN, providing further evidence on the intense competition in $\mathrm{HK}$ construction market environment. It can be seen that the HK proportions of 'bid' responses are identical when $N=4$ to 6 for the booming and scenarios. In other words, the probability of a 'bid' decision is not likely to change if $N \leq 6$ in boom periods in which we expect approximately 75 attempts out of 100 bidding opportunities. This extends to $N \leq 8$ for recession when competition becomes fierce with bidding attempts increased to 85 out of 100 bidding opportunities. The same phenomenon of constant proportions of 'bid' responses can also be seen in SIN case where the probability of a 'bid' decision is not likely to change if $N \leq 6$ in both the booming and recession scenarios (i.e. approximately 55 attempts out of 100 bidding opportunities). The high responsiveness towards bidding opportunities among the $\mathrm{HK}$ and SIN respondents can partly be explained because the relatively small construction markets in these two city states due to geographical size limitations may not able to support the growth of the existing number of firms.

\begin{tabular}{rrrr}
\hline 95\% CI for true difference in proportions of bid & \multicolumn{2}{c}{$\begin{array}{c}\text { Sample odds } \\
\text { ratio }\end{array}$} \\
\cline { 1 - 2 } Lower bound & Upper bound & 0.43 \\
-0.2271 & -0.1849 & 0.92 \\
-0.0387 & -0.0004 & 2.14 \\
0.1705 & 0.2024 & \\
\hline
\end{tabular}

Table 3: Differences in proportions of 'bid' responses and the sample odds ration through paired-group comparisons 


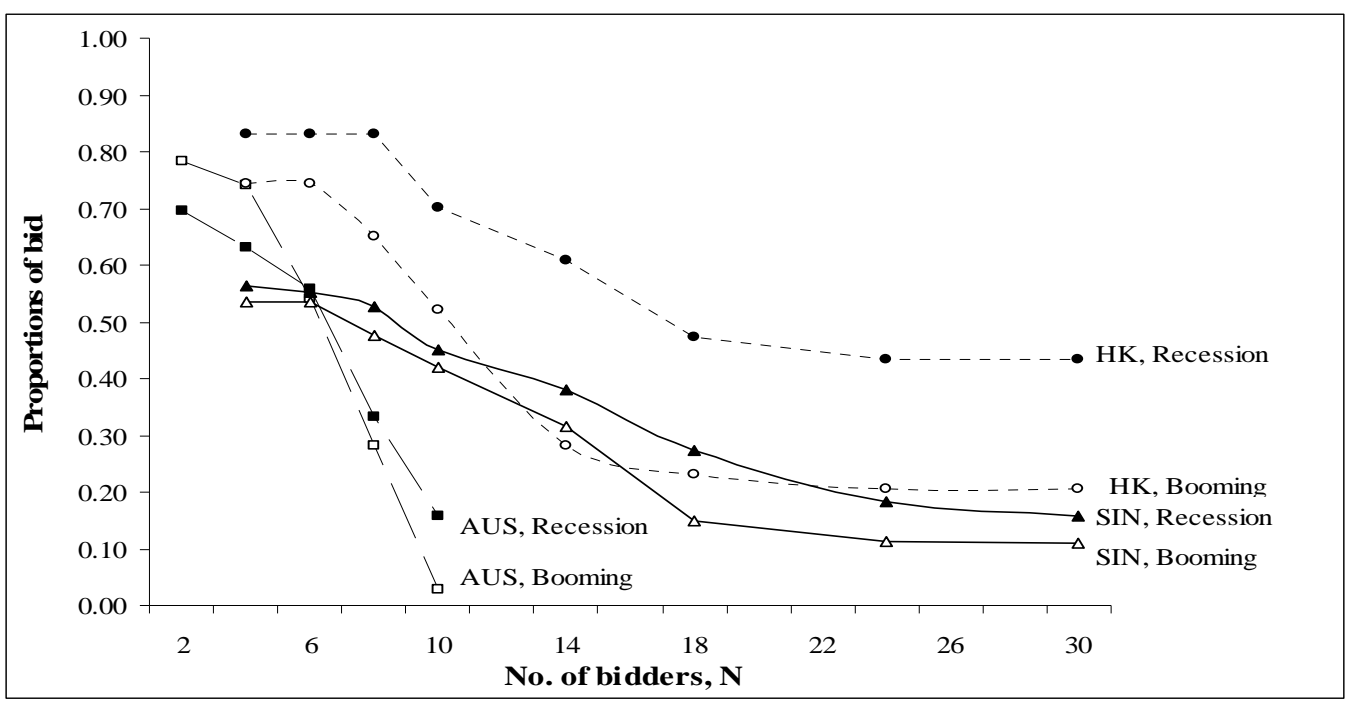

Figure 1: Sample proportions of 'bid' responses according to country I territory, market conditions and number of bidders

Interestingly, the HK respondents' proportions of 'bid' responses in boom times are still higher than the proportions of bid in recession of AUS and SIN for majority of the number of bidders' scenarios. It would seem that the bidding competition within the HK construction market environment akin to 'lottery' game given the high proportions of 'bid' responses. A chancy process which requires the contractors to bid for many jobs that come along. In short, 'if you aren't in you can't win'. In conjunction with the paired-group analysis, the evidence is suggestive that the construction market environment in $\mathrm{HK}$ is the most competitive; this is followed by the SIN and AUS, respectively. This ranking appears to indicate that the lesser the government intervention on bidding competition, the greater will be the intensity of competition and vice versa. Other competitive situations would have to be analysed, and subjected to statistical test, before we could confidently generalize this observation.

\section{CONCLUSIONS}

This paper sets out to explore the AUS, HK and SIN contractors' bid/no-bid decision in response to different intensity of competition according to two extreme market conditions scenarios, i.e. (i) boom times with low need for work, and (ii) recession times with high need for work. Data were collected via a designed experiment so as to make direct comparisons possible.

The experimental results show that all AUS, $\mathrm{HK}$ and SIN respondents adhere to the decreasing probability of winning wherein the proportions of 'bid' responses decrease as the number of bidders increases. Contrary to general belief, it was found that the AUS proportions of 'bid' responses were higher in booming than in recession when $N=2$ to 4 , indicating that some AUS respondents were keener in competition of not more than four bidders notwithstanding the prevailing market conditions. In addition, All AUS respondents' declined to bid when number of bidders exceeded 10, which is in stark contrast to $\mathrm{HK}$ and SIN where most respondents, at least $30 \%$ of them, opted to bid in competition of 30 bidders, even in boom periods. A chi-square test shows that the bid/no-bid responses were significantly different among these three groups of contractors operating in different market environments.

The evidence is suggestive that the construction market environment in $\mathrm{HK}$ is the most competitive with considerably higher proportions of 'bid' responses; this is followed by the SIN and AUS, respectively. This ranking tends to suggest that the lesser the government intervention on bidding competition, the greater will be the intensity of competition and vice versa. In addition, it would seem that the bidding competition within the HK construction market environment akin to 'lottery' game given the high proportions of 'bid' responses. A chancy process which requires the contractors to bid for many jobs that come along. In short, 'if you aren't in you can't win'.

Clearly, it is difficulty to capture all aspects of the complexities involved in contractors' decision to bid behaviour, in this case the 
focus is on market conditions and number of bidders, for contractors operating in different construction market environments. Other factors are possible in similar study to reveal further aspects and with different degrees of emphases. A suggestion for further research is to focus on the extent to which culture (e.g. Chinese vs. Western) affects contractors' competitive behaviour.

\section{ACKNOWLEDGEMENTS}

This research is supported by the Research Grant Council, University Grants Committee of Hong Kong, through Grant CityU 1129/02E. The authors are indebted to anonymous respondents in the bidding experiment for their invaluable responses that formed the basis for empirical analysis in this study. Thanks also go to the National University Singapore for provision of study facilities to carry out data collection in Singapore.

\section{REFERENCES}

Ahmad, I. and Minkarah, I. (1988). Questionnaire survey on bidding in construction. Journal of Management in Engineering, 4(3), 229-243.

Akintoye, A. and Skitmore, M. (1992). Pricing approaches in the construction industry. Industrial Marketing Management, 21,311-318.

Ang, Y. K. and Ofori, G. (2001). Chinese culture and successful implementation of partnering in Singapore's construction industry. Construction Management \& Economics, 19(6), 619-632.

Australian Bureau of Statistics (2004). Private sector construction industry, Australia, 200203 (cat. no. 8772.0). Australian Bureau of Statistics, Canberra.

Australian Procurement and Construction Council (1999). National Code of Practice for the Construction Industry towards best practice guidelines. Australian Procurement and Construction Council, Canberra.

Bajaj, D., Oluwoye, J. and Lenard, D. (1997). An analysis of contractors' approaches to risk identification in New South Wales, Australia. Construction Management \& Economics, 15(4), 363-369.

Building Construction Authority (2005). BCA contractors registry. Singapore Government, Singapore. Available online: http://dir.bca.gov.sg/bca/index.asp

Carr, R. I. (1983). Impact of number of bidders on competition. Journal of Construction Engineering and Management, 109(1), 61-73.
Census and Statistics Department (2004). Principle statistics for all building and civil engineering establishments. Hong Kong SAR Government, Hong Kong. Available online: http://www.etwb.gov.hk/UtilManager/tc/C2004-08-0-1.pdf

Davis Langdon and Seah International (2000). Spon's Asia Pacific construction costs handbook, $3^{\text {rd }}$ ed. E \& F. N. Spon, London.

De Neufville, R. and King, D. (1991). Risk and need-for-work premiums in contractor bidding. Journal of Construction Engineering and Management, 117(4), 659-673.

De Neufville, R., Hani, E. N. and Lesage, Y. (1977). Bidding models: Effects of bidders' risk aversion. Journal of Construction Division, 103(1), 57-70.

Department of Employment and Workplace Relations (2006). Australian Government implementation guidelines for the National Code of Practice for the Construction Industry. Commonwealth of Australia.

Department of Industry, Science and Resources (1999). Building for growth: an analysis of the Australian Building and Construction Industries. Commonwealth of Australia.

Drew, D. and Skitmore, M. (2006). Testing Vickery's revenue equivalence theory in construction auctions. Journal of Construction Engineering \& Management, 132(4), 425-428.

Dulaimi, M. F., Ling, F. and Ofori, G. (2001). Building a world class construction industry: enablers and motivators. National University of Singapore, Singapore.

Dyer, D. (1987). An experimental analysis of auction theory, PhD thesis. University of Houston.

Dyer, D. and Kagel, J, H. (1996). Bidding in common value auctions: how the commercial construction industry corrects for the winner's curse. Management Science, 42(10), 14631475.

Dyer, D., Kagel, J. H. and Levin, D. (1989). A comparison of naive and experienced bidders in common value offer auctions: a laboratory analysis. Economic Journal, 99, 108-115.

Econ (2004). A report for the Office of Fair Trading: Assessing the impact of public sector procurement on competition, available at http://www.oft.gov.uk

Egemen, M. and Mohamed, A. N. (2007). A framework for contractors to reach strategically 
correct bid/no bid and mark-up size decisions. Building and Environment, 42(3), 1373-1385.

Environment, Transport and Works Bureau (2005). List of approved contractors for public works. Hong Kong SAR Government, Hong Kong. Available online: http://www.etwb.gov.hk/index_static.aspx

Fayek, A. and Young, D. M. (1998). A survey of tendering practices in the Australian construction industry. Engineering Management Journal, 10(4), 29-34.

Fayek, A., Ghoshal, I. and AbouRizk, S. (1999). A survey of the bidding practices of Canadian civil engineering construction contractors. Canada Journal of Civil Engineering, 26, 13-25.

Flanagan, R. and Norman, G. (1985) Sealed bid auctions: an application to the building industry. Construction Management \& Economics, 3(2), 145-161.

Friedman, L. (1956). A competitive bidding strategy. Operations Research, 4(1), 104-112.

Hackemer, G. C. (1970). Profit and competition: estimating and bidding. Building Technology and Management, Dec, 6-7.

Hillebrandt, P.M. (2002). Economic theory and the construction industry. Macmillan Press Ltd., London.

King, M. and Mercer, A. (1990). The optimum markup when bidding with uncertain costs. European Journal of Operational Research, 47, 348-363.

Lasserre, P. and Probert, J. (1998). Competing in Asia Pacific: understanding the rules of the game. Long Range Planning, 30(1), 30-50.

Male, S. Strategic management in construction: conceptual foundations. In Competitive Advantage in Construction (edited by S.P. Male and R. Stocks editors), p. 1-4. Butterworth-Heinemann, Oxford.

Meikle, J. L. (1990). International comparisons of construction costs and prices. Habitat International, 14(2/3), 185-192.

Ngai, S. C., Drew, D. S., Lo, H. P. and Skitmore, M. (2002). A theoretical framework for determining the minimum number of bidders in construction bidding competitions. Construction Management \& Economics, 20(6), 473-482.

Odusote, O. O. and Fellows, R. F. (1992). An examination of the importance of resource considerations when contractors make project selection decisions. Construction Management \& Economics, 10(2), 137-151.
Ofori, G. (1996). International contractors and structural changes in host country construction industries: case of Singapore. Engineering Construction \& Architectural Management, 3(4), 271-288.

Ofori, G. and Chan, S. L. (2001) Factors influencing development of construction enterprises in Singapore. Construction Management \& Economics, 19(2), 145-154.

Oo, B. L. and Drew, D. (2005). The bidding environments of Hong Kong and Singapore construction industries. In Proceedings of 2005 International Conference on Construction \& Real Estate Management (edited by $\mathrm{Y}$. Wang. and Q. Shen), p. 65-70. Penang, Malaysia.

Pries, F. and Janszen, F. (1995). Innovation in the construction industry: the dominant role of the environment. Construction Management \& Economics, 13(1), 43-51.

Runeson, K. G. (1988). Methodology and method for price-level forecasting in the building industry. Construction Management \& Economics, 6(1), 49-55.

Shash, A. A. (1993) Factors considered in tendering decisions by top UK contractors. Construction Management \& Economics, 11(2), 111-118.

Skitmore, M. (1989). Contract Bidding in Construction, Longman, Harlow.

Skitmore, M. (2002) Raftery curve construction for tender price forecasts. Construction Management \& Economics, 20(1), 83-89.

The Straits Times (2004). Budget terminal: 28 firms bid for job, Singapore.

Thorpe, T. and McCaffer, R. (1991) Competitive bidding and tendering policies. In Competitive Advantage in Construction (edited by S.P. Male and R. Stocks editors), p. 163194. Butterworth-Heinemann, Oxford.

Underhill, E. (2003) The Australian construction industry: union control in a disorganized industry. In Building Chaos (edited by G. Bosch and P. Philips), p.114-137. Routledge, London.

Wilson, O. D., Atkin, A.S., Sharpe, K. and Kenley, R. (1987). Competitive tendering: the ideal number of tenders. In Managing Construction Worldwide (edited by P. R. Lansley and P. A. Marlow), p. 175-186. E. \& F. N. Spon, London. 